\title{
A Search of the Efficient S-Hetarylsuccinate Landscape Design Plant Growth Stimulators
}

\author{
Svitlana O. Yakovleva-Nosar ${ }^{1}$, Natalia P. Derevyanko ${ }^{1,2}$, Alina S. Yevlash ${ }^{1}$, Oleksandr A. Brazhko ${ }^{1}$, \\ Mykhailo P. Zavhorodnii ${ }^{1,2}$, Volodymyr V. Tkach ${ }^{3 *}$ (D) , Petro I. Yagodynets ${ }^{3}$

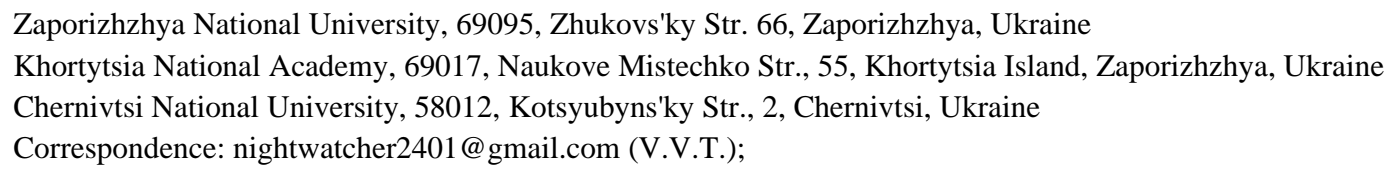

Scopus Author ID 55758299100

Received: 15.03.2021; Revised: 12.04.2021; Accepted: 14.04.2021; Published: 20.04.2021

\begin{abstract}
The 4-thioquinolinic succinate derivatives with potential growth-stimulating activity has been investigated. The monitoring of carbohydrate concentration has confirmed its stimulation of the metabolism in saffron and sugarbeet. This lets us conclude that it may be an excellent growth stimulator.
\end{abstract}

Keywords: quinoline-4-thiol; growth stimulation; saffron; sugarbeet.

(C) 2021 by the authors. This article is an open-access article distributed under the terms and conditions of the Creative Commons Attribution (CC BY) license (https://creativecommons.org/licenses/by/4.0/).

\section{Introduction}

The search for new ways and methods of plant growth stimulation and quality enhance is one of the most important tasks of modern plant physiology and biochemistry [1-2]. The condition of the achievements, in this case, is the realization of plant genetic potential and diminishing the negative influences of the ambient factors in their ontogenesis [3-4].

The growth and productivity regulators permit us to regulate plant productivity, the reason why they are widely used in agriculture. These substances are natural plant hormones and their synthetic analogs. They possess a vast and rich spectrum of action over plant organisms, and their use permits the regulation of the behavior on some plant growth and development stages to mobilize the plants' possibilities.

First of all, it has to let it use the light energy efficiently to enhance the plastic substances' synthesis with their further delivery to the agriculturally precious tissues and organs [5-7].

The development of new plant growth regulators for gardening is based on the synthetic modification of the natural or known synthetic structures, taking into account the enhancement of their activity and diminishing the adverse negative effects. Aza-heterocycles form one of the most studied effective and less-toxic groups of substances, widely investigated in this aspect [1-9].

Nowadays, our interest in succinic acid and derivatives as growth regulators has been enhanced. Its growth stimulation, bioavailability, and biodegradability rates are very high. The substance has a positive effect on the soil microflora.

Unfortunately, the succinic acid exact mechanism of action over plant organisms hasn't been depicted yet. On the other hand, the influence of the succinic acid on the growing seed 
metabolism has already been illustrated in literature, including its influence on phosphorus metabolism [9-20], enhancing the oxygen absorption by plant organism.

Thus, our work aims to synthesize the investigation of the succinate derivative growth regulator. Also, the work includes the experimental verification of the use of the (disodium 22-methylquinolin-4-yl)thio)succinate in landscape design plant growth

\section{Materials and Methods}

The salt has been obtained by a known procedure, described in [1]. The physicochemical and spectral data are correspondent to the literature data [1].

The investigation objects included the plant species Crocus chrysanthus, Romance, Crocus grandiflora, Grandmaitre, and C. Grandiflora Mix. The glucose, fructose, and saccharose concentration in Crocus have been described following the methodology of Pochynok, and the amylum content was detected per the methodology of Yastrembovych and Kalinin [2, 3]. The analyses were carried on after the massive blossoming in 2018. All the experimental matrixes were composed of 12 variants. The experimental data were treated by statistical methods.

\section{Results and Discussion}

As it is known, the succinic acid is Krebs cycle intermediate. Nevertheless, its mechanism of action has not been studied enough. The seed metabolism activation during the growth has already been described in the literature. It also confirms the 6 to $8 \%$ enhancement of field similarity of the sugar beet, like enhancing the harvest mass and leaf area. The sugar yield per area was also enhanced due to more fertile harvest and better sugar content. The conclusion was that it was possible to use the succinic acid for pre-seed treatment of both seeds and vegetating plants.

Table 1. The influence of growth stimulator on carbohydrate content in saffron (\% per dry substance $n=3, x \pm$ $\mathrm{SD})$

\begin{tabular}{c|l|c|c|c}
\multirow{3}{*}{ Specimen } & Values & Reducing carbohydrates & Starch & Total carbohydrates \\
& Variants & $3,35 \pm 0,054$ & $4,81 \pm 0,513$ & $43,06 \pm 2,878$ \\
\hline \multirow{3}{*}{ I } & Reference & $3,32 \pm 0,059$ & $4,13 \pm 0,212$ & $35,64 \pm 1,781$ \\
\cline { 2 - 5 } & 25 & $2,01 \pm 0,095^{* * *}$ & $4,00 \pm 0,031$ & $30,70 \pm 1,342^{*}$ \\
\cline { 2 - 5 } & 50 & $1,75 \pm 0,129^{* * *}$ & $4,75 \pm 0,119$ & $27,89 \pm 1,865^{* *}$ \\
\cline { 2 - 5 } & 100 & $2,69 \pm 0,095$ & $5,06 \pm 0,031$ & $34,22 \pm 1,067$ \\
\hline \multirow{3}{*}{ II } & Reference & $0,85 \pm 0,151^{* * *}$ & $5,00 \pm 0,244$ & $24,81 \pm 0,977^{* *}$ \\
\cline { 2 - 5 } & 25 & $0,71 \pm 0,046^{* * *}$ & $6,88 \pm 0,506^{*}$ & $17,15 \pm 1,111^{* * *}$ \\
\cline { 2 - 5 } & 50 & $0,52 \pm 0,069^{* * *}$ & $5,31 \pm 0,394$ & $15,93 \pm 1,045^{* * *}$ \\
\cline { 2 - 5 } & 100 & $2,68 \pm 0,105$ & $5,06 \pm 0,031$ & $48,90 \pm 1,343$ \\
\hline \multirow{2}{*}{ III } & Reference & $2,29 \pm 0,087^{*}$ & $5,06 \pm 0,163$ & $31,89 \pm 1,779^{*}$ \\
\cline { 2 - 5 } & 25 & $1,68 \pm 0,109^{* *}$ & $6,88 \pm 0,506^{*}$ & $19,49 \pm 1,505^{* * *}$ \\
\cline { 2 - 5 } & 50 & $1,04 \pm 0,079^{* * *}$ & $5,31 \pm 0,388$ & \\
\cline { 2 - 5 } & 100 & Herein: $*-\mathrm{P}<0,05 ; * *-\mathrm{P}<0,01 ; * * *-\mathrm{P}<0,001$ & \\
\end{tabular}

We have analyzed a succinic acid derivative influence to reduce sugars content, starch content, and total carbohydrate concentration.

The results of the investigation, shown in Table 1, let us conclude that in either reference or the stimulated specimen, the fructose amount is higher than the glucose amount. By an increase of the concentration of the stimulator, the reducing carbohydrates content decreases. 
The same trend is observed by the evaluation of saccharose content and total carbohydrate content. Yet, the starch content in the treated and reference specimen remains nearly the same.

Therefore, it is possible to conclude that the succinate-derived stimulator activates the metabolism in plants.

\section{Conclusions}

The results of investigations let us conclude that the S-hetarylsuccinate derivatives are effective growth regulators. Their use for the development of vegetating plants of landscape design enhances the product quality.

Therefore the search for the growth-stimulating action among the S-hetaryl-substituted derivatives may be useful for modern agriculture.

\section{Funding}

This research received no external funding.

\section{Acknowledgments}

This research has no acknowledgments.

\section{Conflicts of Interest}

The authors declare no conflict of interest.

\section{References}

1. Ulishchenko, E.A; Brazhko, O.A.; Omelyanchyk, L.A., Gencheva, V.I; Brazhko, O.O. Computer Forecast to Biological Activity of Some N-Acyl-Substituted-S-(2-Methylquinoline-4-yl)-L-Cysteine, Pyt. Bioindykats. Ekol., 2011, 16, 168 - 182, Link: http://sites.znu.edu.ua/bioindication/issues/2011-16-2/_lishc.pdf, in Ukrainian

2. Labenska, I. B.; Shapoval, G.S; Kruglyak, O. S.; Omelyanchyk, L.A.; Brazhko, O.A.; Zavhorodnii, M.P; The Dependence of the Biological Activity of 6-Alkoxy-2-Methyl-4-Mercaptoquinoline N-Acyl Derivatives, on the Substituent in the $6^{\text {th }}$ Position of Heterocycle, Ukr. Biochem. J.; 2010, 82, 49 - 54, Link: http://ubj.biochemistry.org.ua/images/stories/pdf/ubj3_2010/Labenska_82_3.pdf, in Ukrainian

3. Brazhko, O.A.; Kornet, M.M.; M. P. Zavgorodniy, Pat. 97937 Ukraine, IPC C07D 215/36, C07D 219/04, C07D 221/06, C07D 221/16, C07D 319/14. No. 2011 11474; stated. 28.09.2011; published March 26, 2012 Bull No. 6. $10 \mathrm{p}$

4. Filimonov, D.A.; Lagunin, A.A.; Gloriozova, T.A.; Rudik, A.V.; Druzhilovskii, D.S.; Pogodin, P.V.; Poroikov, V.V. Prediction of the Biological Activity Spectra of Organic Compounds Using the Pass Online Web Resource. Chemistry of Heterocyclic Compounds 2014, 50, 444-457. https://doi.org/10.1007/s10593014-1496-1.

5. Yelenich, I.P.; Rassukana, Y.; Khomutnyk, Y.; Kornet, M.; Brazhko, A.; Synytsia, A.D.; Onys'ko, P.P Synthesis, The Antioxidant and Antibacterial Activity of Fluoroalkyl Substituted Thiazolidinones and Thiazinanones, incorporating an aminophosphonate or aminocarboxylate fragment. J. Org. Pharm. Chem. 2014, 47, 45-48. https://doi.org/10.24959/ophcj.14.814.

6. Shapoval, G.S.; Kruglyak, O.S. Electrochemical modeling of antioxidants action and determination of their activity. Russian Journal of General Chemistry 2011, 81. https://doi.org/10.1134/S1070363211070073.

7. Marchelek-Mysliwiec, M.; Wilk, A; Turon-Skrzypinska, A.; et al. Acute Kidney Injury Related to Wild Mushrooms Intoxication. J. Educ. Health. Sport. 2020, 10, 42-46. https://doi.org/10.12775/JEHS.2020.10.01.005.

8. Dinis-Oliveira, R.J.; Soares, M.; Rocha-Pereira, C.; Carvalho, F. Human and Experimental Toxicology of Orellanine. Hum. Exp. Toxicol., 2016, 35, 1016-1029. https://doi.org/10.1177/0960327115613845. 
9. Beaumier, M.; Rioult, J.P.; Georges, M. et al., Mushroom Poisoning Presenting With Acute Kidney Injury and Elevated Transaminases. Nephrol. Rounds., $2018, \quad 4, \quad 877-881$. https://doi.org/10.1016/j.ekir.2019.02.016.

10. Khovpachev, A.A.; Basharin, V.A.; Chepur, S.V. et al. The Modern State of Art of The High Mushroom Toxins. Nitrogen-Containing Compounds, Uspekhi. Sovr. Biol. 2020, 140, 378-394. https://doi.org/10.31857/S0042132420040092.

11. Xin, Yu; Wang, N; Wang, Ch. et al. Electrochemical Detection of Hydroquinone and Catechol with Covalent Organic Framework Modified Carbon Paste Electrode, J. Electroanal. Chem. 2020, 877, 114530. https://doi.org/10.1016/j.jelechem.2020.114530.

12. Karthika, A; Ramasamy Raja, V.Karuppasamy, P. et al. A Novel Electrochemical Sensor for Determination of Hydroquinone in Water Using $\mathrm{FeWO}_{4} / \mathrm{SnO}_{2}$ Nanocomposite Immobilized Modified Glassy Carbon Electrode. Arab. J. Chem. 2020, 13, 4065-4081. https://doi.org/10.1016/j.arabjc.2019.06.008.

13. Kumar, Y.; Vashistha, V.K.; Das, D.K. Synthesis of Perovskite-type $\mathrm{NdFeO}_{3}$ nanoparticles and used as electrochemical sensor for detection of paracetamol. Lett. Appl. Nanobiosci. 2020, 9, 866-869. https://doi.org/10.33263/LIANBS91.866869.

14. de Sá, A.C.; Barbosa, S.C.; Raymundo-Pereira, P.A. et al. Flexible Carbon Electrodes for Electrochemical Detection of Bisphenol-A, Hydroquinone and Catechol in Water Samples. Chemosensors 2020, 8, 103. https://doi.org/10.3390/chemosensors8040103.

15. Koçak, Ç. C; Koçak, S. Enhanced Electrochemical Determination of Catechol and Hydroquinone Based on Pd Nanoparticles/Poly(Taurine) Modified Glassy Carbon Electrode. Electroanalysis 2020, 32, 500. https://doi.org/10.1002/elan.201900500.

16. Mashhadizadeh, M.H.; Kalantarian, S.M.; Azhdeh, A. A Novel Electrochemical Sensor for Simultaneous Determination of Hydroquinone, Catechol and Resorcinol Using a Carbon Paste Electrode, Modified by ZnMOF, Nitrogen-Doped Graphite and AuNPs. Electroanalysis 2020, 32, 326. https://doi.org/10.1002/elan.202060326.

17. Manjunatha, J. Poly(Adenine) Modified Graphene-Based Voltammetric Sensor for the Electrochemical Determination of Catechol, Hydroquinone and Resorcinol. The Open Chemical Engineering Journal 2020, 14, 52 - 62. https://doi.org/10.2174/1874123102014010052.

18. Ahmad, Kh.; Kumar, P.; Mobin, Sh. A Highly Sensitive and Selective Hydroquinone Sensor Based on a Newly Designed N-rGO/SrZrO $3 \quad$ Composite. Nanoscale Adv. 2020, $2, \quad 502$. https://doi.org/10.1039/c9na00573k.

19. Romero-Montero, A.; del Valle, L.J.; Puiggali, J. et al. Poly(Gallic Acid)-Coated Polycaprolactone Inhibits Oxidative Stress in Epithelial Cells. Mat. Sci. Eng. C. 2020, 115, 111154. https://doi.org/10.1016/j.msec.2020.111154.

20. Zamudio-Cuevas, Y.; Andonegui-Elguera, M. Aparicio-Juarez, A. et al. The Enzymatic Poly(Gallic Acid) Reduces Pro-Inflammatory Cytokines in vitro, a Potential Application in Inflammatory Diseases, Inflammation 2020, 44, 174-185. https://doi.org/10.1007/s10753-020-01319-5.

21. Yang, P.; Zhang, Sh.; Cheng, X. et al. Recent Developments in Polydopamine Fluorescent Nanomaterials. Mater. Horiz. 2020, 7, 746-761. https://doi.org/10.1039/c9mh01197h.

22. Zmerli, I.; Michel, J.P.; Makky, A. Bioinspired Polydopamine Nanoparticles: Synthesis, Nanomechanical Properties and Efficient PEGylation Strategy. J. Mat. Chem. B. 2020, 8, 4489-4504. https://doi.org/10.1039/c9tb02769f.

23. Murari, G.; Bock, N.; Zhou, H, et al. Effects of Polydopamine Coatings of Nucleation Modes of Surface Mineralization from Simulated Body Fluid. Sci. Rep. 2020, 10, 14982. https://doi.org/10.1038/s41598-02071900-3.

24. Li, H.; Xi, J.; Donaghue, A.G. et al., Synthesis and Catalytic Performance of Polydopamine Supported Metal Nanoparticles. Sci. Rep. 2020, 10, 10416. https://doi.org/10.1038/s41598-020-67458-9.

25. Wang, Z.; Zou, Y.; Li, Y. et al. Metal-Containing Polydopamine Nanomaterials: Catalysis, Energy and Theranostics. Small 2020, 16, 18. https://doi.org/10.1002/smll.201907042.

26. Jin, A.; Wang, Y.; Lin, K.; Jiang, L. Nanoparticles Modified by Polydopamine: Working as Drug Carriers, Bioact. Mat. 2020, 5, 522-541. https://doi.org/10.1016/j.bioactmat.2020.04.003.

27. Gargioni, Ch.; Borzenkov, M.; D'Alfonso, L. et al. Self-Assembled Monolayers of Copper Sulfide Nanoparticles on Glass as Antibacterial Coatings. Nanomaterials 2020, 10, 352. https://doi.org/10.3390/nano10020352. 
28. Rajaram, R.; Kiruba, M.; Suresh, Ch. et al. Amperometric Determination of Myo-Inositol Using a Glassy Carbon Electrode Modified with Nanostructured Copper Sulfide. Microchim. Acta 2020, 187, 334. https://doi.org/10.1007/s00604-020-04300-z.

29. Alshahrani, L.A; Miao, L.; Zhang, Y. et al. 3D-Flower-Like Copper Sulfide Nanoflake-Decorated Carbon Nanofragments-Modified Glassy Carbon Electrodes for Simultaneous Electrocatalytic Sensing of CoExisting Hydroquinone and Catechol. Sensors 2019, 19, 2289. https://doi.org/10.3390/s19102289.

30. Malakootian, M.; Hamzeh, S.; Mahmoudi-Moghaddam, H. A Novel Electrochemical Sensor Based on $\mathrm{FeNi}_{3} / \mathrm{CuS} / \mathrm{BiOCl}$ Modified Carbon Paste Electrode for Determination of Bisphenol A. Electroanalysis 2020, 32, 205. https://doi.org/10.1002/elan.202060205.

31. Das, I.; Goel, N.; Agrawal, N.R.; Gupta, S.K. Growth patterns of dendrimers and electric potential oscillations during electropolymerization of pyrrole using mono-and mixed surfactants. J. Phys. Chem. B 2010, 114, 12888-12896. https://doi.org/10.1021/jp105183q.

32. Das, I.; Goel, N.; Gupta, S.K.; Agrawal, N.R. Electropolymerization of pyrrole: Dendrimers, nano-sized patterns and oscillations in potential in presence of aromatic and aliphatic surfactants. Journal of Electroanalytical Chemistry 2012, 670, 1-10. https://doi.org/10.1016/j.jelechem.2012.01.023.

33. Tkach, V.V.; Kushnir, M.V.; Ivanushko, Y.G.; de Oliviera, S. The Theoretical Description for Neotame Electrochemical Determination, Assisted by Vanadium Oxyhydroxide Composite with a Squarainic Dye. Appl. J. Env. Eng. Sci. 2020, 6, 109-115. https://doi.org/10.48422/IMIST.PRSM/ajees-v6i2.18524.

34. Tkach, V.V.; Kushnir, M.V.; de Oliveira, S.C. et al., Electrochemical Determination of Sudan Dyes and Two Manners to Realize it: a Theoretical Investigation. Lett. Appl. NanoBioSci. 2020, 9, 1451-1458. https://doi.org/10.33263/LIANBS94.14511458. 